
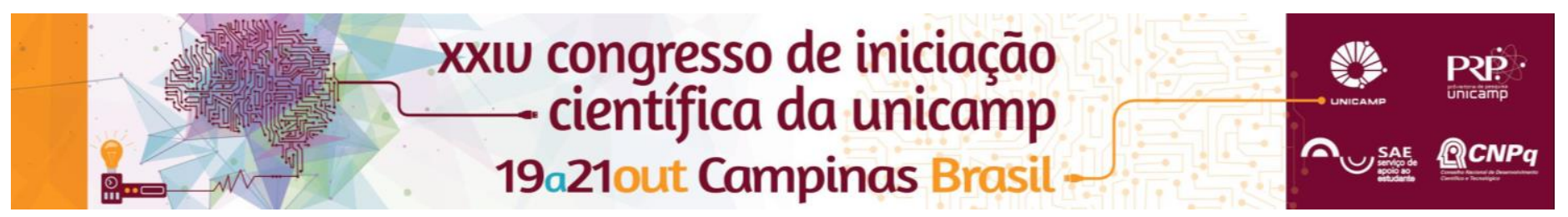

\title{
O Fenômeno "Glee" na Indústria Fonográfica.
}

\section{Felipe Augusto Trevisanutto.}

\begin{abstract}
Resumo
Este trabalho foi desenvolvido objetivando a investigação e análise das características da série de TV estadunidense "Glee" a partir de abordagens pertinentes encontradas tanto na literatura quanto em fontes alternativas de informação, comparando-as com dados gerados fruto de análise empírica. Desta maneira, o produto resultante tenta explicá-la como fenômeno midiático e sobretudo fonográfico, em tempos que a Indústria Fonográfica passa por transformações nos seus modos de operação tradicionais.
\end{abstract}

\section{Palavras-chave:}

Glee, série de TV, indústria fonográfica.

\section{Introdução}

A série Glee teve sua de estreia no dia 19 de maio de 2009 no horário nobre da televisão nos Estados Unidos, e seu desfecho no dia 20 de março de 2015. Ao longo de suas seis temporadas, o programa de televisão que mistura comédia, drama e música foi um fenômeno de audiência e midiático, movimentando diversos setores da indústria cultural; e uma das primeiras a impactar e gerar interações nas redes sociais. Como produto audiovisual, a série foi prestigiada com dezenas de prêmios, incluindo o Globo de Ouro e o Emmy Awards.

Não muito diferente, sua trilha musical, característica do seu gênero, foi um dos maiores sucessos que a indústria fonográfica já teve, resultando no lançamento de dezenas de álbuns e turnês de shows com o elenco pela América do Norte e países europeus. Glee é classificado como o artista que entrou mais vezes com singles nos gráficos da Billboard Hot100, 207 vezes ao todo, batendo o recorde que já foi Elvis Presley e Lil Wayne'.

Entretanto, a facilidade de disseminação de material musical pela internet sem necessidade de pagamento de direitos autorais - um dos fatores principais que sustentam a indústria fonográfica - é uma realidade cada vez mais presente no comportamento dos usuários na rede.

Então, buscar entender como a série conseguiu superar este cenário nada favorável para a indústria fonográfica é essencial para compreender não só seu sucesso, mas também compreender como se comportam e se adaptam as partes envolvidas.

\section{Resultados e Discussão}

Como produto audiovisual, Glee investe no gênero musical, tradicionalmente importante na indústria cultural, sobretudo no cinema e no teatro. Durante a pesquisa, foi averiguado que para a televisão esta tendência se repete, considerando que já existem séries com temáticas musicais desde a década de 1960 . Tal tendência cresce progressivamente até o explosão dos musicais juvenis na TV e cinema na década de 2000, acompanhada dos programas de talentos, que criaram um cenário perfeito para o estudo de caso da pesquisa.

A análise dos números musicais apresentados em Glee, na sua maioria, revelam uma característica bastante distinta das performances: elas se assemelham a estrutura do videoclipe. Em muitas das vezes, são recriações.

DOI: 10.19146/pibic-2016-51860
A recriação, seja das performances ou da grande maioria da sua trilha musical, justifica seu sucesso mercadológico, uma vez que traz à tona a necessidade de imitação imposta pela indústria cultural ${ }^{2}$ e questões referentes a sua autenticidade e aura, já que a série (re)significa as obras originais ao reproduzi-las ${ }^{3}$.

O uso de produtos e ícones bem sucedidos da indústria fonográfica ao invés da originalidade mostra uma necessidade dessa indústria em sempre resgatar $e$ homenagear seu próprio passado ${ }^{4}$, e Glee cumpre esse papel, já que cria a sensação de nostalgia na audiência. Experiências e sensações são muito apreciadas pelos millennials e que convencidos, as compram.

\section{Conclusões}

Toda vez que há um cenário favorável, as indústrias tentam lucrar e Glee foi uma dessas apostas pensadas estrategicamente, a visar o público de millennials até atingir gerações anteriores com 0 resgate de produtos culturais passados e presentes. A imposição de sua própria aura nos produtos que ela (re)significa e de um ambiente nostálgico, gera a sensação de experiência de pertencimento que vende e é onde a indústria fonográfica de beneficia. Esta última, conclui-se que enfrenta sua crise se transformando perante as necessidades: se antes a venda de discos indicava seu sucesso e a pirataria online era só mais um dos seus empecilhos, hoje ela diversifica seus produtos e modos de disseminação.

\section{Agradecimentos}

Agradeço ao Conselho Nacional de Desenvolvimento Cientifico e Tecnológico (CNPq), ao PIBIC/UNICAMP, ao meu orientador Professor José Eduardo Ribeiro de Paiva e minha amiga Heloísa Dias Fahl por todo o apoio.

\footnotetext{
1 TRUST, Gary. 'Glee' Graduates at the Head of the Class on Billboard Hot 100. Billboard. [Online]. Mar. 2015. Disponível em: $<$ http://www.billboard.com/articles/chart-beat/6509293/glee-graduates-head-ofthe-class-hot-100>.

${ }^{2}$ ADORNO, Theodor. O iluminismo como mistificação das massas. In: Indústria Cultural e Sociedade. São Paulo, SP: Paz e Terra, 2002. p. 5 - 44

${ }^{3}$ BENJAMIN, Walter. A obra de arte na era de sua reprodutibilidade técnica. Primeira Versão. Cotia: Instituto Sidarta, 2011. 14 p.

${ }^{4}$ REYNOLDS, Simon. Retromania: Pop Culture's Addiction To Its Own Past. London: Faber \& Faber, c2011. 496p. il. ISBN 0865479941.
} 